\title{
Serial whole-body cryotherapy in fibromyalgia is effective and alters cytokine profiles
}

\author{
Philipp Klemm ${ }^{1 *} \mathbb{D}$, Johanna Becker ${ }^{1}$, Iris Aykara ${ }^{1} \mathbb{D}$, Thomas Asendorf ${ }^{2} \mathbb{D}$, Gabriel Dischereit ${ }^{1} \mathbb{D}$, Elena Neumann ${ }^{1} \mathbb{D}$, \\ Ulf Müller-Ladner ${ }^{1}$ and Uwe Lange ${ }^{1}$ (D)
}

\begin{abstract}
Introduction: Whole-body cryotherapy (WBC) has shown to be beneficial in the treatment of fibromyalgia (FM). There is cumulative evidence that cytokines play a crucial role in FM. It's unknown whether clinical effects of WBC can be demonstrated at the molecular level and how long the effects last.

Methods: We compared effects of serial WBC (6 sessions $\left(-130^{\circ} \mathrm{C}\right.$ in 6 weeks) in FM patients and healthy controls $(\mathrm{HC})$. Primary outcome was the change in pain level (visual analogue scale 0-100 mm) after 6 sessions. Secondary outcomes were a change in disease activity (revised Fibromyalgia Impact Questionnaire) and pain after 3 sessions and 3 months after discontinued therapy and in cytokine levels (interleukin (IL-)1, IL-6, tumor necrosis factor a (TNFa) and IL-10). The patients' opinions on the satisfaction, effectiveness and significance of WBC were evaluated.

Results: Twenty-three FM patients and $30 \mathrm{HC}$ were enrolled. WBC resulted in a significant reduction in pain and disease activity after 3 and 6 sessions. No clinical benefit could be measured 3 months after discontinued treatment. Overall, probands were satisfied with WBC and considered WBC to be important and effective. FM patients had significantly different levels of IL-1, IL-6, TNF- $a$ and IL-10 at each reading point compared to HC. Levels of IL-1, IL-6 and IL-10 were significantly altered over time in FM patients. Compared to HC FM patients showed a significantly different response of IL $1,-6$ and -10 to WBC.

Conclusion: Serial WBC is a fast acting and effective treatment for FM. Proven effects of WBC may be explained by changes in cytokines.
\end{abstract}

Keywords: Whole-body cryotherapy, Fibromyalgia, Cytokines, Physical therapy, Fibromyalgia impact questionnaire

\section{Introduction}

Fibromyalgia (FM) is a chronic pain syndrome. It is characterized by widespread pain and somatic symptoms such as fatigue, sleep disorders, cognitive impairment and depressive disorders [1]. Women around the age of 50 are affected more frequently $[2,3]$. The global mean prevalence of FM is $2.7 \%$ [4]. Not only can FM lead to a high level of individual impairment, but it has been

\footnotetext{
* Correspondence: p.klemm@kerckhoff-klinik.de

'Department of Rheumatology, Immunology, Osteology and Physical Medicine, Justus-Liebig-University Giessen, Campus Kerckhoff, Bad Nauheim, Germany

Full list of author information is available at the end of the article
}

calculated that even a minimal increase in the Fibromyalgia Impact Questionnaire (FIQ) score increases costs in Europe by approximately $€ 865$ per year [5]. FM is therefore a problem of high social importance and represents a high economic burden [6].

The pathogenesis of FM is elusive. However, several factors seem to be of importance. These include abnormal pain sensitivity and pain inhibition $[7,8]$, a disturbed hypothalamic-pituitary-adrenal axis $[9,10]$ and cytokine dysregulation [11]. In addition, both genetic and environmental factors seem to play a role $[7,8]$. Eventually, there is increasing evidence of neurogen- derived inflammatory mechanisms [12]. These affect

(c) The Author(s). 2021 Open Access This article is licensed under a Creative Commons Attribution 4.0 International License, which permits use, sharing, adaptation, distribution and reproduction in any medium or format, as long as you give appropriate credit to the original author(s) and the source, provide a link to the Creative Commons licence, and indicate if changes were made. The images or other third party material in this article are included in the article's Creative Commons licence, unless indicated otherwise in a credit line to the material. If material is not included in the article's Creative Commons licence and your intended use is not permitted by statutory regulation or exceeds the permitted use, you will need to obtain permission directly from the copyright holder. To view a copy of this licence, visit http://creativecommons.org/licenses/by/4.0/. 
peripheral tissues as well as the spinal cord and brain and involve a variety of neuropeptides, chemokines, and cytokines. Both the innate and adaptive immune system appear to be activated in this process [12] and could play an essential role. In neuropathic pain, for example, a balance between pro-inflammatory and anti-inflammatory cytokines is crucial, so that, an imbalance ultimately leads to pain and impaired pain processing [13, 14]. Indeed, in neuropathic pain models, pharmacological blocking of the pro-inflammatory cytokines interleukin (IL-)1, IL-6 and tumor necrosis factor $\alpha$ (TNF- $\alpha$ ) has been found to prevent or reverse allodynia and hyperalgesia [15].

Whole-body cryotherapy (WBC) exposes patients to extremely cold dry air in an environmentally controlled chamber or cabin for a short period of time (usually between 1 and $5 \mathrm{~min}$ ). The exposure to cold air induces vasoconstriction [16] and stimulation of dermal thermoreceptors, which leads to slower nerve conduction [17] ultimately resulting in an analgesic effect. So far, it has been used as a recovery technique after physical exercise [18] and has been successfully tested in inflammatory diseases such as rheumatoid arthritis $[19,20]$ and ankylosing spondylitis [19, 21]. In addition to its symptomatic and immediate effects, WBC has been shown to affect the immune system. In healthy controls WBC leads to an increase in white blood cell count, especially lymphocytes and monocytes. It also affects the overall oxidative and antioxidative status, which indicates an increased immune capacity [22]. Furthermore, WBC has an influence on cytokine levels: it has been shown to increase IL- 6 and IL-10 levels and to decrease IL- $1 \alpha$ levels in healthy individuals [23]. In a pilot study, a significant improvement in IL-1 and TNF- $\alpha$ levels could be observed in patients with inflammatory rheumatic diseases [19]. At the other end of the thermotherapy spectrum, it has been shown that hyperthermia also alters cytokine levels [24]. Nowadays, physical therapy has been shown to change molecular parameters, which explains its profound and beneficial effects in rheumatic diseases [25].

Recently WBC has shown effects in the treatment of FM: it reduces pain [26, 27], fatigue [26] and improves health-reported quality of life [26-28]. Positive effects of serial WBC (10 sessions in 8 days) are still remarkable 1 month after discontinued treatment [28]. An effect on disease activity measured by the revised Fibromyalgia Impact Questionnaire (FIQR) has not yet been reported.

We conducted a controlled, prospective trial to investigate WBC's effects on pain and disease activity and possible changes in molecular parameters (cytokine levels of IL-1, -6, - 10 and TNF- $\alpha$ ) in FM and healthy controls (HC). To evaluate the long-term effects, we also examined relevant parameters 3 months after WBC treatment.

\section{Materials and methods \\ Participants}

Patients with FM and HC were treated at Campus Kerckhoff of Justus-Liebig University Gießen, Dept. of Rheumatology, Immunology, Osteology and Physical Medicine. Eligible participants had to be between 18 and 80 years old. Only patients with primary FM were eligible and the diagnosis of primary FM had to be confirmed on the basis of the 2016 revised 2010/11 diagnostic criteria of FM [29]. HC was not allowed to have a medical history. In the case of women, a commitment not to become pregnant during the trial was obtained. We excluded patients with secondary FM, participants with a disease for which WBC is contraindicated, e.g. unstable coronary disease, heart attack in the last 6 months, active vasculitis or acute infection, participants with a body weight over $120 \mathrm{~kg}$ or intolerance to cold. All patients with FM had to be in stable pharmacological and non-pharmacological treatment 4 weeks prior to the start of the study. During the entire study period of 3 months no change in pharmacological treatment or non-pharmacological treatment (such as mind-bodytherapy or meditative movement) was allowed. In addition, no physical therapy such as massages or multicomponent therapy was allowed during the entire duration of the study.

\section{Study procedures}

In this controlled prospective study, all participants received WBC treatment ( 6 sessions at $-130^{\circ}$ for 3 weeks with 2 sessions/week). Outcomes were measured after 3 and 6 sessions and 3 months after discontinued therapy (follow-up).

WBC treatment was delivered using a cryosauna, SPACE CABIN' ( 230 V, $50 \mathrm{~Hz}$, serial number: 1050, year of manufacture: 2013) from Cryomed s.r.o., Slowakia. The therapy was delivered to participants in swimsuit/underwear and warm socks. Fingers were placed under the armpits during the treatment to avoid frostdamages. Temperatures between -110 to $-170{ }^{\circ} \mathrm{C}$ can be applied. In this study, a fixed temperature of $-130^{\circ} \mathrm{C}$ was selected. The first session was set at $90 \mathrm{~s}$., the second at $120 \mathrm{~s}$ and from the third session onwards a time of $180 \mathrm{~s}$ (3 $\mathrm{min})$ was set.

\section{Assessments and outcomes}

Primary outcome was a change in pain intensity measured by a visual analogue scale (VAS) from baseline after 6 WBC sessions in patients with FM. The measurement of pain intensity with a $10 \mathrm{~cm}$ VAS, visually representing the amplitude of pain (0 (best) to 100 (worst) $\mathrm{mm}$ ) experienced by the subject [30] is well-established for FM [31]. The minimum clinically important 
difference (MCID) for pain intensity measured with VAS has been reported to be 2.1 points (respectively $21 \mathrm{~mm}$ ) [32].

The secondary outcome was a change in the baseline pain level (VAS) after 3 sessions of WBC and 3 months of discontinued therapy in patients with FM. In addition, the disease activity measured by the FIQR was assessed after 6 sessions of WBC and after 3 months of discontinued therapy. The FIQR [33] evaluates 21 items in the 3 areas of function $(n=9)$, overall impact $(n=2)$, and symptoms $(n=10)$ of FM. Each item can be rated from 0 (best) to 10 (worst). The domain scores are then divided individually and added in a final step creating a total FIQR score from 0 (best) to 100 (worst). The results of the total FIQR can be adequately compared with the results of older papers reported using the original FIQR [33]. Thus, although no MCID for the FIQR has been reported, the MCID of a 14\% change appears important for the FIQR [34].

The study used ELISA to detect changes in cytokine levels (IL-1, IL-6, IL-10 and TNF- $\alpha$ ) in FM patients and $\mathrm{HC}$ after 3 and $6 \mathrm{WBC}$ sessions and after 3 months of discontinued therapy. To reduce artificially altered cytokine levels, blood samples were immediately cooled and taken to the laboratory. For each sample taken, a time of less than $30 \mathrm{~min}$ from collection to centrifugation was recorded. Serum was centrifuged at $3500 \mathrm{rpm}$ at $15^{\circ} \mathrm{C}$ for $10 \mathrm{~min}$ and plasma was centrifuged at $2850 \mathrm{rpm}$ at $4{ }^{\circ} \mathrm{C}$ for $15 \mathrm{~min}$. The samples were stored at $-80^{\circ} \mathrm{C}$ until further use. Cytokine levels (IL-10, IL-6, TNF- $\alpha$ and IL$1 \beta / \mathrm{IL}-1 \mathrm{~F} 2)$ were measured in sera using Quantikine ${ }^{\circ}$ ELISAs (R\&D Systems) according to the manufacturer's instructions. Optical readings were taken with the SUNRISE (TECAN) system at $450 \mathrm{~nm}$. So far it could be determined that FM patients apparently have different levels of cytokines compared to HC. However, there are neither established ranges of cytokines for FM patients nor a solid correlation between specific concentrations and disease activity [35].

After $6 \mathrm{WBC}$ sessions, the subjective satisfaction, efficacy and significance of WBC were assessed.

\section{Sample size}

We calculated that a sample size of 18 will have $89,2 \%$ power to detect a difference in pain (VAS 0-10 cm) in means of 1,6, assuming a standard deviation of differences of 2, using a paired t-test with a $5 \%$ two-sided significance level. Assuming a dropout rate of $20 \%$ we aimed to recruit 20 patients. The considered difference in means and standard deviation are conservative estimates based on previous studies evaluation the reduction of pain (VAS) while treating FM by WBC. Calculations were performed in nQuery 8.

\section{Statistical analysis}

Summary statistics (mean, standard deviation, frequencies, and percentages) were used to describe the sample. Differences between groups were tested with t-tests assuming unequal variances. Differences to baseline were tested with t-tests for paired values. All $p$-values are displayed unadjusted. The global hypothesis was tested by analysis of variance (ANOVA) and p-values less than 0.05 were considered statistically significant. In paired comparisons the p-values are displayed without adjustment, but after Bonferroni-Holm adjustment for multiplicity,they are shown statistically significant. The analyses were performed with R Version 3.6.1.

\section{Results}

From July 2014 to July 2015 we screened 89 patients (32 $\mathrm{HC}$ and 57 patients with the diagnosis of FM). Of these, 57 participants (26 FM patients, $31 \mathrm{HC}$ ) met the inclusion criteria and were enrolled (Fig. 1). The main reason for the exclusion was that FM was in the background of an inflammatory rheumatic disease and was therefore not diagnosed as "primary FM" (Fig. 1). The mean age of the participants was $46 \pm 9.8$ years, $66 \%$ were female.

In FM patients the mean duration of the disease was $13.9 \pm 8$ years $(n=23$; disease duration: min. 1 year; max. 35 years). Three $\mathrm{FM}$ patients (nausea $1 \mathrm{x}$, unspecific maculae $1 \mathrm{x}$, private reasons $1 \mathrm{x})$ and one $\mathrm{HC}(1 \mathrm{x}$ acute urinary infection) dropped out during treatment. A statistical analysis was therefore carried out with $23 \mathrm{FM}$ patients and 30 controls (Fig. 1).

\section{Primary outcome}

The mean $( \pm S D)$ pain levels measured by VAS in FM patients changed from $5.91 \pm 2.3 \mathrm{~mm}$ (confidence interval (CI) 4.9 to 6.92 ) at baseline to $3.43 \pm 2.8 \mathrm{~mm}$ (CI 2.2 to 4 , $7)$ after 6 WBC sessions $(p<0.0001)$. The MCID for pain levels of at least 2.1 was achieved.

\section{Secondary outcomes}

The mean $( \pm \mathrm{SD})$ pain levels measured by VAS in FM patients changed from $5.91 \pm 2.3 \mathrm{~mm}$ (CI 4.9 to 6.92 ) at baseline to $4 \pm 2.7 \mathrm{~mm}$ (CI 2.8 to 5,2$)$ after $3 \mathrm{WBC}$ sessions $(p=0.0016)$. The MCID for pain levels of at least 2.1 was not achieved.

3 months after the last WBC session, the pain levels measured by VAS were $71.7 \pm 1,89 \mathrm{~mm}$ (CI 6.3 to 8$)$, rising to values above the baseline $(p=0.0037)$ (Supplement-Table 1).

Disease activity assessed by FIQ decreased significantly from a mean $( \pm$ SD) FIQ $60.7 \pm 18.4$ at the start of the study to mean FIQ $48.5 \pm 23$ after WBC treatment ( $p=$ 0.0006). Three months after discontinued treatment the mean FIQ returned to baseline level of $64.1 \pm 15.4$ ( $p=$ 


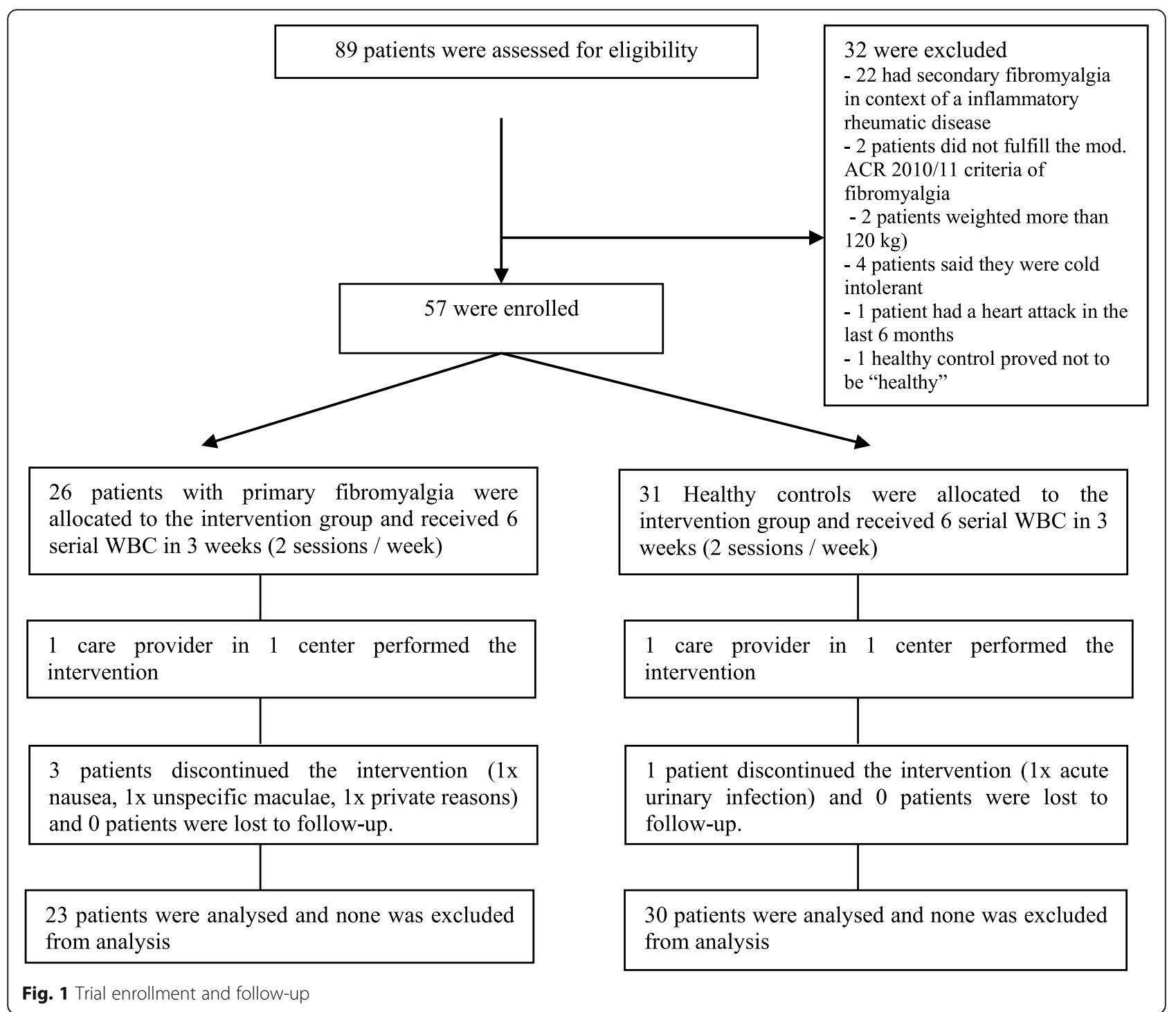

0.2142) (Fig. 2 and Supplement-Table 1). The MCID of $14 \%$ for a change in FIQ was missed (here 12.2\%).

IL-1 levels in FM patients decreased significantly after $3 \mathrm{WBC}$ sessions and after $6 \mathrm{WBC}$ sessions and remained significantly lower compared to baseline 3 months after discontinued WBC treatment. Interestingly, 3 months after the last WBC, IL-1 levels in both groups had decreased compared to baseline, although healthy controls showed no significant change during treatment. In comparison FM patients showed significantly higher IL-1 levels after 3 sessions and 3 months after the last WBC session than healthy controls at the start of treatment (see Fig. 3 and Supplemental Table 2).

IL-6 levels were decreased by WBC in both groups. While IL-6 levels in healthy individuals returned to baseline after 3 months without WBC, FM patients still showed decreased levels. In FM patients, IL-6 levels were significantly reduced by WBC after 3 sessions and after
6 sessions compared to baseline. 3 months after the last treatment IL-6 was also significantly improved. In contrast to healthy controls, FM patients showed significantly decreased IL-6 levels at each reading point compared to baseline (cf. Figure 3 and SupplementTable 3).

TNF- $\alpha$ levels were not significantly decreased by WBC, neither in FM patients nor in healthy controls (cf. Figure 3 and Supplement-Table 4).

Levels of IL-10 in FM patients were significantly influenced after 3 WBC applications and 3 months after discontinued treatment. Compared to healthy controls, FM patients showed significantly higher IL-10 levels at baseline, after 6 WBC sessions and 3 months after the last WBC application (cf- Fig. 3 and Supplement-Table 5).

Taken together, in an analysis of mixed effects, the concentrations of IL-1, IL-6 and IL-10 as well as pain (VAS) and disease activity (FIQ) were significantly 

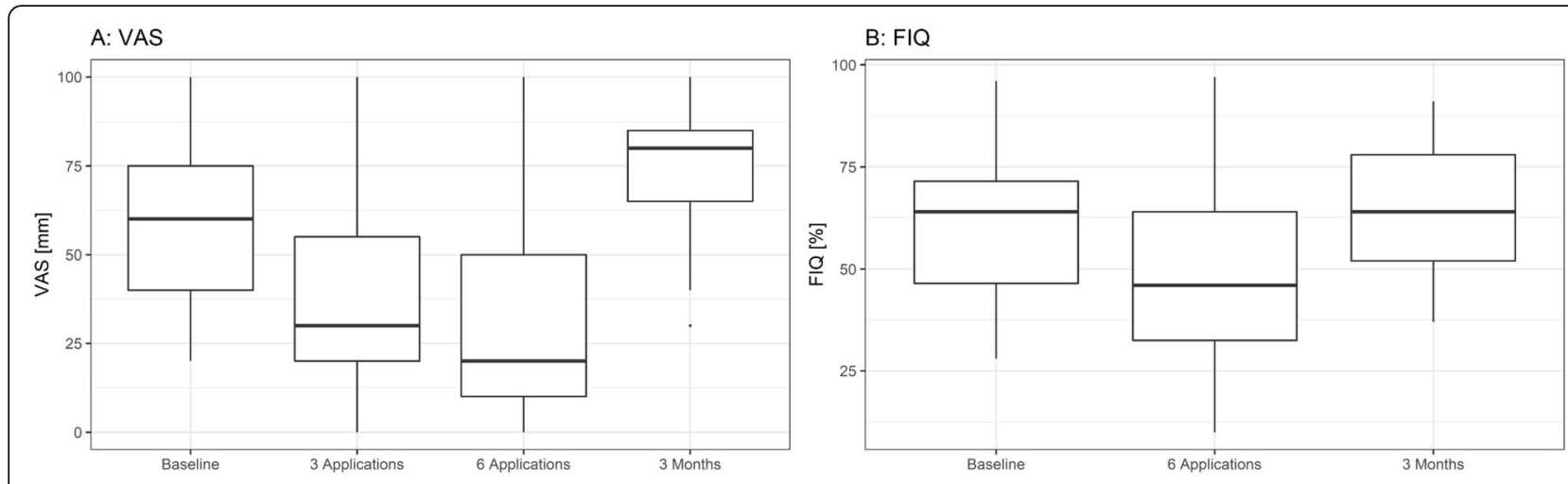

Fig. 2 Course of VAS (a) and FIQ (b)

altered over time by WBC treatment. FM patients had significantly different levels of IL-1, IL-6, TNF- $\alpha$ and IL10 at each reading point compared to healthy controls. Most interestingly, FM patients showed a significantly different response to WBC compared to healthy controls in terms of changes in IL1, -6 and -10 to WBC over time (cf. Table 1).
Subjective satisfaction, efficacy and significance of WBC After completing WBC treatment, patients were asked to report on their subjective satisfaction with WBC treatment and on the subjective effectivness and significance of WBC treatment. Most patients were highly satisfied with WBC and perceived WBC as an effective and highly important treatment option (cf. Figure 4).

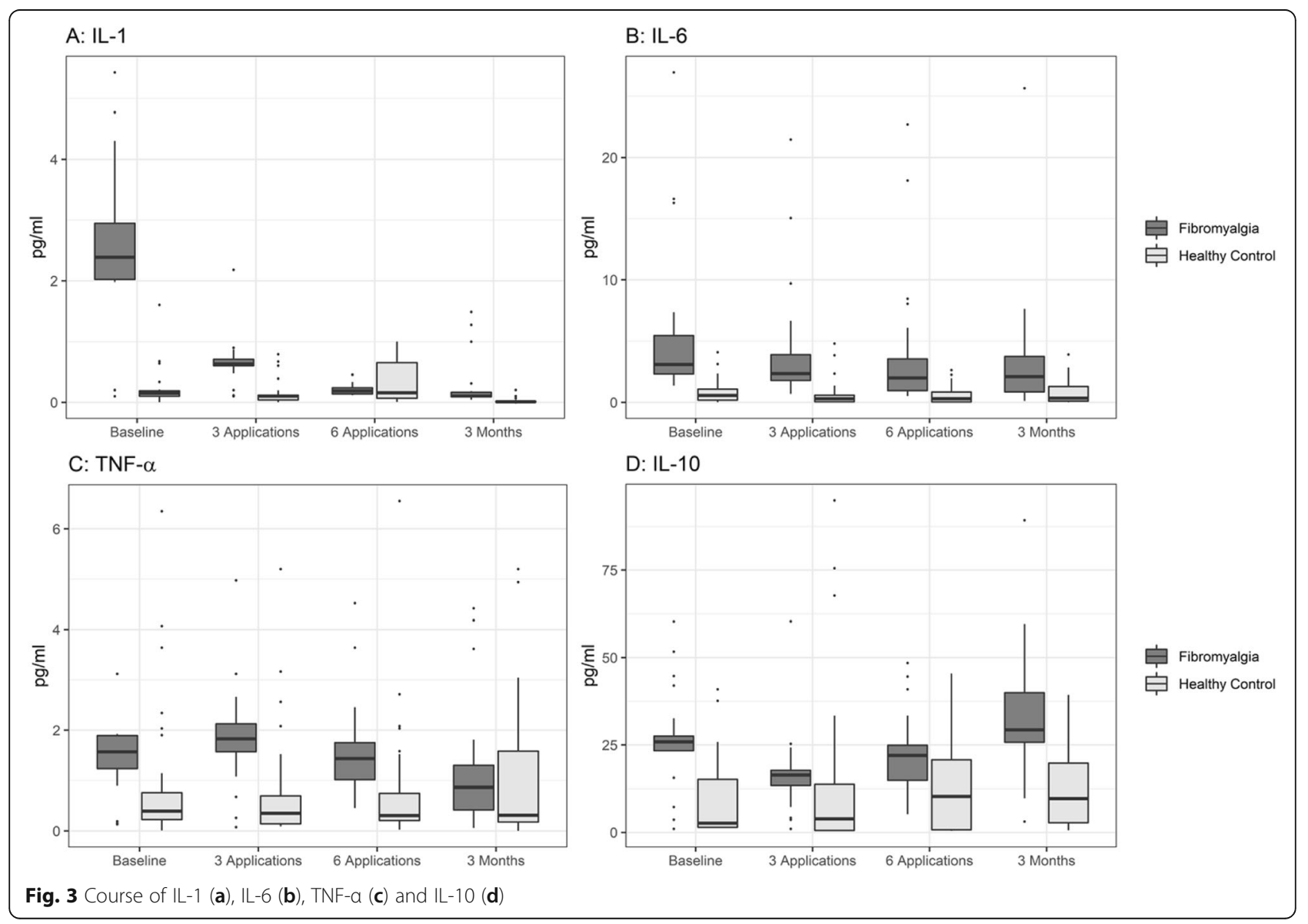


Table 1 Mixed effects analysis of group effects (Fibromyalgia vs. Healthy Control) and time effects (Baseline, 3 Applications, 6 Applications, 3 Months) as well as interaction. A significant interaction effect indicates differences in value development/ performance over time depending on the cohort

\begin{tabular}{llll}
\hline & Group Effect & Time Effect & Interaction \\
\hline IL1 & $p<0.0001$ & $p<0.0001$ & $p<0.0001$ \\
IL6 & $p=0.0005$ & $p=0.0009$ & $p=0.0053$ \\
IL10 & $p=0.0008$ & $p=0.0032$ & $p<0.0001$ \\
TNF-alpha & $p=0.0096$ & $p=0.8783$ & $p=0.1271$ \\
VAS & - & $p<0.0001$ & - \\
FIQ & - & $p<0.0001$ & - \\
\hline
\end{tabular}

\section{Discussion}

This trial, which examined the clinical and molecular effects of WBC in FM patients and HC, showed that serial WBC (6 sessions) resulted in a significant and clinically important pain reduction in FM patients. Secondary outcomes showed that disease activity is significantly reduced by WBC and that the effects on pain are significantly manifested after only $3 \mathrm{WBC}$ sessions. The subjects were satisfied with WBC and considered WBC to be important and effective. FM patients had significantly different levels of IL-1, IL-6, TNF- $\alpha$ and IL-10 at each reading point compared to HC. Levels of IL-1, IL-6 and IL-10 were significantly altered over time in FM patients. In comparison to healthy controls, FM patients showed a significantly different response in IL1, -6 and - 10 levels to WBC.

Three previous studies have already tested the effect of WBC on FM, but with different settings. Bettoni et al. treated recruited patients with mandatory aerobic exercise (cycloergometer or treadmill) for $30 \mathrm{~min}$ immediately after WBC treatment [26]. Because aerobic exercise is effective in the treatment of FM [36] and physical activity could have influenced WBC treatment by vasodilatation as opposed to WBC-induced vasoconstriction, the distinct role of WBC in the effects observed in this study was limited. Therefore, we tested without background physical therapy throughout the study and had patients in stable treatment before and during the trial. In the study of Rivera et al. the cross-over design did not work because of too short wash-out periods: patients treated with WBC did not initially return to baseline with regard to VAS and FIQ, so that only results of the first sequence could be reported [27]. Vitenet et al. only treated 11 FM patients with WBC to investigate changes in the Medical Outcome Study Short Form-36 and, which is why the study is limited due to sample size [28]. So far, only Rivera et al. investigated effects of WBC on FIQ [27] and only Vitenet et al. included a follow-up showing

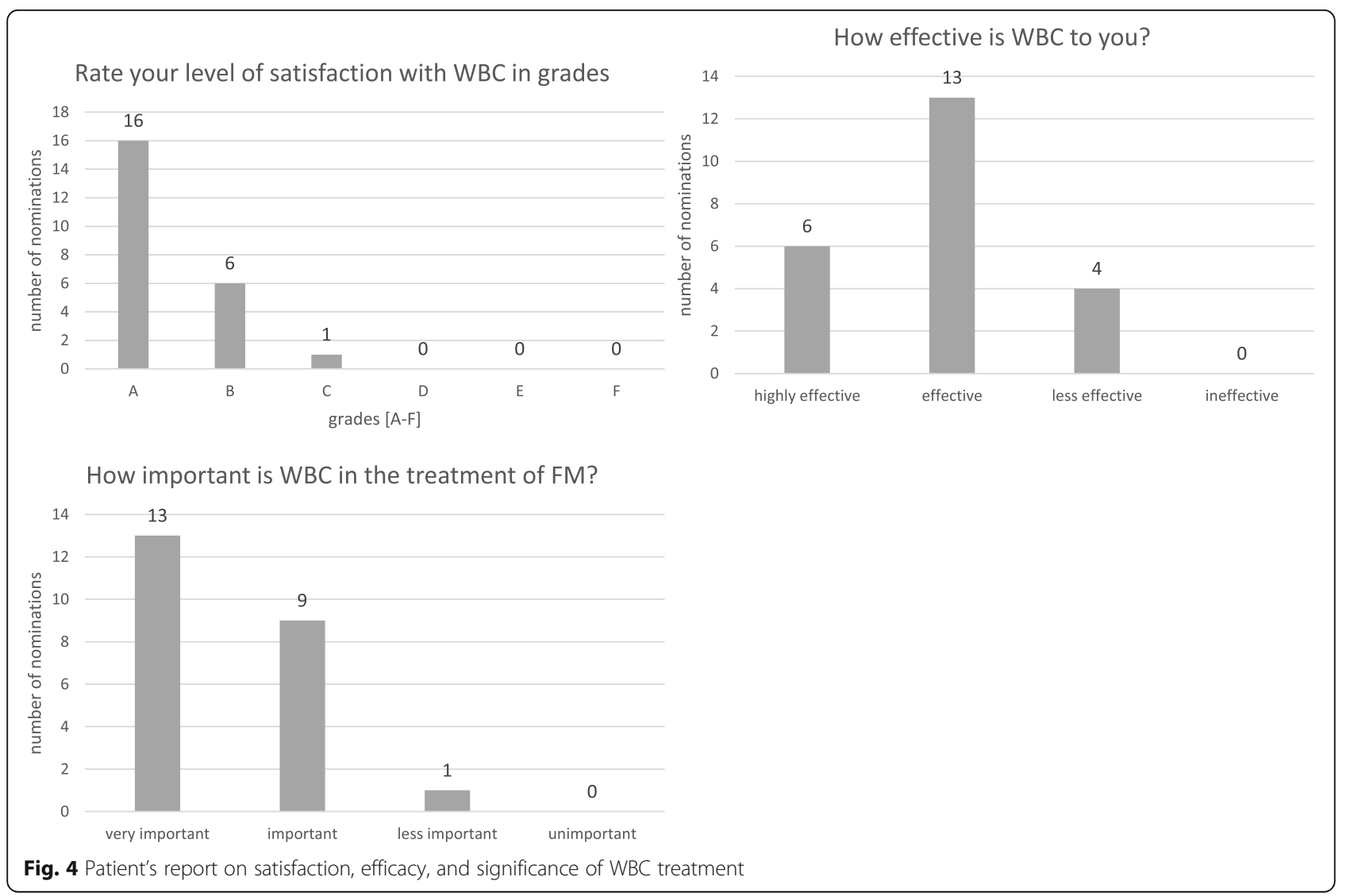


effects of WBC 1 month after discontinued treatment [28]. The clinically beneficial effects of WBC in this study appear to be consistent with previous studies.

This study is limited by the absence of an FM control group, that would not receive WBC. As previous studies already tested such settings and thus demonstrated the proposed clinical benefits of WBC, we focused on a slightly different aspect in this study and investigated molecular effects of WBC in addition to the clinical effects. Thus, we first had to confirm the clinical effects of WBC in order to test the molecular effects in comparison to a healthy control group in a second step.

In our study the acceptance of WBC was high, as most patients reported to be highly satisfied with WBC while perceiving $\mathrm{WBC}$ as an effective and highly important treatment option. Therefore, WBC seems to be an effective tool to improve disease activity. Interestingly, a reduction of pain and disease activity was reported after only 3 sessions with a prolonged effect with increasing serial applications. Since patients with FM are partially impaired in their ability to work [37] and a minimal increase in the FIQ score increased costs by approximately $€ 865$ per year [5], cost-effective WBC can be of great benefit in the treatment of acute exacerbations of FM in an individual, but it can also be important in a social perspective.

Until now, it was not known how long the beneficial effects of WBC on FM would last after treatment. Rivera et al. had problems with their cross-over design as the washout period of 1 week for the first WBC group proved to be too short, confirming an effect of WBC for at least 1 week. Vitenet et al. showed that effects of serial WBC (10 sessions over 8 days) lasted for over 1 month after the last treatment [28]. Our study shows that 3 months after stopping treatment, effects of WBC on pain and disease activity were no longer reduced. Hence, serial WBC (between 6 and 10 sessions in up to 3 weeks) had effects for more than 1 month after termination of WBC treatment, which then decreased over time and were not effective after 3 months.

Overall, WBC seems to be a clinically valid, good and fast-acting treatment for FMS.

In the pathogenesis of FM-related hyperalgesia, central pain amplification, known as central sensitization, plays a major role $[8,38-40]$. Additionally, an imbalance of pro- and anti-inflammatory cytokines plays a role in pain induction and maintenance and is known to be altered in FM $[11,35]$. Prostaglandin synthesis is increased by IL-1 alone or in combination with TNF- $\alpha$. It regulates substance $\mathrm{P}$ gene expression, thereby lowering the pain threshold in peripheral nerves [41]. In addition, the injected IL-1 causes fever, headache, myalgia and arthralgia [42] - symptoms that FM patients regularly experience. In this context, IL-1RA (IL-1 receptor antagonists) have been found to be higher in FM patients [43]. So far, not all FM patients have been found to have elevated TNF- $\alpha[11,44]$, but the use of TNF inhibitors has been shown to be less effective in secondary FM [45]. IL-6 can be associated with hyperalgesia, depression stress, fatigue and sympathetic nervous system activation. Several studies have therefore measured IL-6 levels in FM - with varying results. Overall, a metaanalysis by Üceyler et al. favoured the detection of elevated plasma levels of IL-6 in FM [35]. Interleukin-10 (IL-10) inherits many anti-inflammatory properties. The expression of substance $\mathrm{P}$ is regulated by IL-10 in a way that the pain threshold is increased. Furthermore, IL-10 decreases the production of IL- 1 , IL- 6 and TNF- $\alpha$. In addition, WBC has proven to have an influence on cytokines in healthy controls [23].

While previous studies hypothesized the cause of WBC effects in FM [26-28], we found that WBC treatment significantly altered not only disease activity but also levels of IL-1, IL- 6 and IL-10 over time. FM patients had significantly different levels of IL-1, IL-6, TNF- $\alpha$ and IL-10 at each reading point compared to healthy controls. These differences in cytokines we found correlate well with a study by Ernberg et al. comparing circulating cytokines between FM and healthy controls with the mentioned findings of Üceyler et al. [35] and Lubkowska et al. [23]. Ernberg et al. investigated the effect of 15 weeks of progressive resistance exercise or relaxation therapy on cytokine levels in FM patients and $\mathrm{HC}$ without significant alterations in cytokines and clinical outcomes in FM patients [44]. In accordance with our findings, Ernberg et al. found that FM patients had significantly different levels of cytokines compared to $\mathrm{HC}$, which play a substantial role in inflammation but also pain modulation [44]. As IL-1, IL-6 and IL-10 play an essential role in pain, the observed changes could clearly explain the observed efficacy of WBC.

\section{Conclusion}

WBC is effective in FM and reduces the burden of disease. The effects of serial WBC are strongest during application and are diminished 3 months after WBC treatment. Moreover, the significant long-term alteration of IL-1, IL-6 and IL-10 by WBC could explain these beneficial effects.

\section{Supplementary Information}

The online version contains supplementary material available at https://doi. org/10.1186/s42358-020-00159-z.

\section{Additional file 1}

Acknowledgements

We thank all participants. 


\section{Consent to participate}

Study details and protocol were verbally explained to all participants and written information sheets were delivered. Written informed consent was obtained from each participant.

\section{Consent to publication}

Consent to publication was obtained from all participants and all authors.

\section{Registration}

The study was retrospectively registered DRKS00021218 at www.drks.de (German Clinical Trials Register) on the 8th of April 2020

\section{Authors' contributions}

All authors contributed to the study conception and design. Material preparation, data collection and analysis were performed by PK, JB, GD, TA and UL. The first draft of the manuscript was written by PK, UL and IA and all authors commented on previous versions of the manuscript. All authors read and approved the final manuscript

\section{Funding}

Not applicable. The study did not receive any funding.

\section{Availability of data and materials}

Data and material can be requested from PK on reasonable request.

\section{Ethics approval and consent to participate}

The study was conducted in accordance to the Declaration of Helsinki and approved by the Medical Ethical Comittee of Justus-Liebig-University Gießen (registration number AZ 09/14).

\section{Competing interests}

All author declare no conflicts of interest.

\section{Author details}

${ }^{1}$ Department of Rheumatology, Immunology, Osteology and Physical Medicine, Justus-Liebig-University Giessen, Campus Kerckhoff, Bad Nauheim, Germany. ${ }^{2}$ Department of Medical Statistics, University Medical Center Göttingen, Göttingen, Germany.

Received: 13 October 2020 Accepted: 22 December 2020

Published online: 13 January 2021

\section{References}

1. Wolfe F, Clauw DJ, Fitzcharles MA, et al. The American College of Rheumatology preliminary diagnostic criteria for fibromyalgia and measurement of symptom severity. Arthritis Care Res. 2010;62:600-10. https://doi.org/10.1002/acr.20140.

2. Wolfe F, Ross K, Anderson J, et al. The prevalence and characteristics of fibromyalgia in the general population. Arthritis Rheum. 1995;38:19-28. https://doi.org/10.1002/art.1780380104.

3. Wolfe F, Smythe HA, Yunus MB, et al. The american college of rheumatology 1990 criteria for the classification of fibromyalgia. Arthritis Rheum. 1990;33:160-72. https://doi.org/10.1002/art.1780330203.

4. Queiroz LP. Worldwide epidemiology of fibromyalgia. Curr Pain Headache Rep. 2013;17:356. https://doi.org/10.1007/s11916-013-0356-5.

5. Spaeth M. Epidemiology, costs, and the economic burden of fibromyalgia. Arthritis Res Ther. 2009;11:117.

6. Knight T, Schaefer C, Chandran A, et al. Health-resource use and costs associated with fibromyalgia in France, Germany, and the United States. Clin Outcomes Res. 2013;5:171-80. https://doi.org/10.2147/CEOR.S41111.

7. Bradley LA. Pathophysiology of fibromyalgia. Am J Med. 2009;122:S22-30. https://doi.org/10.1016/j.amjmed.2009.09.008.

8. Häuser W, Ablin J, Fitzcharles M-A, et al. Fibromyalgia. Nat Rev Dis Primers. 2015;1:15022. https://doi.org/10.1038/nrdp.2015.22

9. Crofford LJ, Pillemer SR, Kalogeras KT, et al. Hypothalamic-pituitary-adrenal axis perturbations in patients with fibromyalgia. Arthritis Rheum. 1994;37: 1583-92. https://doi.org/10.1002/art.1780371105.

10. Tak LM, Cleare AJ, Ormel J, et al. Meta-analysis and meta-regression of hypothalamic-pituitary-adrenal axis activity in functional somatic disorders Biol Psychol. 2011;87:183-94.
11. Rodriguez-Pintó I, Agmon-Levin N, Howard A, Shoenfeld Y. Fibromyalgia and cytokines. Immunol Lett. 2014;161:200-3. https://doi.org/10.1016/j.imlet. 2014.01.009

12. Littlejohn G, Guymer E. Neurogenic inflammation in fibromyalgia. Semin Immunopathol. 2018;40:291-300.

13. Ahrens $\mathrm{C}$, Schiltenwolf $\mathrm{M}$, Wang $\mathrm{H}$. Cytokines in psychoneuroendocrine immunological context of nonspecific musculoskeletal pain. Schmerz. 2012; 26:383-8. https://doi.org/10.1007/s00482-012-1153-5.

14. Kiguchi N, Kobayashi Y, Kishioka S. Chemokines and cytokines in neuroinflammation leading to neuropathic pain. Curr Opin Pharmacol. 2012; 12:55-61.

15. Wolf G, Gabay E, Tal M, et al. Genetic impairment of interleukin-1 signaling attenuates neuropathic pain, autotomy, and spontaneous ectopic neuronal activity, following nerve injury in mice. Pain. 2006;120:315-24. https://doi. org/10.1016/j.pain.2005.11.011

16. Mourot L, Cluzeau C, Regnard J. Hyperbaric gaseous Cryotherapy: effects on skin temperature and systemic vasoconstriction. Arch Phys Med Rehabil. 2007;88:1339-43. https://doi.org/10.1016/j.apmr.2007.06.771.

17. Algafly AA, George KP. The effect of cryotherapy on nerve conduction velocity, pain threshold and pain tolerance. Br J Sports Med. 2007;41:365-9. https://doi.org/10.1136/bjsm.2006.031237.

18. Rose C, Edwards KM, Siegler J, et al. Whole-body Cryotherapy as a recovery technique after exercise: a review of the literature. Int J Sports Med. 2017;38: 1049-60. https://doi.org/10.1055/s-0043-114861.

19. Lange U, Uhlemann C, Müller-Ladner U. Serial whole-body cryotherapy in the criostream for inflammatory rheumatic diseases. A pilot study. Med Klin. 2008;103:383-8. https://doi.org/10.1007/s00063-008-1056-5.

20. Bouzigon R, Grappe F, Ravier G, Dugue B. Whole- and partial-body cryostimulation/cryotherapy: current technologies and practical applications. J Therm Biol. 2016:61:67-81.

21. Stanek A, Cholewka A, Gadula J, et al. Can whole-body cryotherapy with subsequent kinesiotherapy procedures in closed type cryogenic chamber improve BASDAI, BASFI, and some spine mobility parameters and decrease pain intensity in patients with ankylosing spondylitis? Biomed Res Int. 2015: 2015:404259. https://doi.org/10.1155/2015/404259.

22. Lubkowska A, Szygula Z, Klimek AJ, Torii M. Do sessions of cryostimulation have influence on white blood cell count, level of IL6 and total oxidative and antioxidative status in healthy men? Eur J Appl Physiol. 2010;109(1):6772.

23. Lubkowska A, Szyguła Z, Chlubek D, Banfi G. The effect of prolonged wholebody cryostimulation treatment with different amounts of sessions on chosen pro-and anti-inflammatory cytokines levels in healthy men. Scand J Clin Lab Invest. 2011;71:419-25. https://doi.org/10.3109/00365513.2011.580859.

24. Lange U, Dischereit G. Effects of different iterative whole-body hyperthermia on pain and cytokines in rheumatic diseases: a current review. Aktuelle Rheumatol. 2018. https://doi.org/10.1055/s-0044-101543.

25. Lange U, Müller-Ladner U, Dischereit G. Rheumatic diseases and molecular physical medicine - new aspects. Phys Medizin, Rehabil Kurortmedizin. 2017:27:205-10. https://doi.org/10.1055/s-0043-113045.

26. Bettoni $L$, Bonomi FG, Zani $V$, et al. Effects of 15 consecutive cryotherapy sessions on the clinical output of fibromyalgic patients. Clin Rheumatol. 2013;32:1337-45. https://doi.org/10.1007/s10067-013-2280-9.

27. Rivera J, Tercero MJ, Salas JS, et al. The effect of cryotherapy on fibromyalgia: a randomised clinical trial carried out in a cryosauna cabin. Rheumatol Int. 2018:38:2243-50. https://doi.org/10.1007/s00296-018-4176-0.

28. Vitenet M, Tubez F, Marreiro A, et al. Effect of whole body cryotherapy interventions on health-related quality of life in fibromyalgia patients: a randomized controlled trial. Complement Ther Med. 2018;36:6-8. https://doi. org/10.1016/j.ctim.2017.10.011.

29. Wolfe F, Clauw DJ, Fitzcharles MA, et al. 2016 revisions to the 2010/2011 fibromyalgia diagnostic criteria. Semin Arthritis Rheum. 2016:46:319-29. https://doi.org/10.1016/j.semarthrit.2016.08.012.

30. Bijur PE, Silver W, Gallagher EJ. Reliability of the visual analog scale for measurement of acute pain. Acad Emerg Med. 2001:8:1153-7. https://doi. org/10.1111/j.1553-2712.2001.tb01132.x

31. Casale R, Rainoldi A. Fatigue and fibromyalgia syndrome: clinical and neurophysiologic pattern. Best Pract Res Clin Rheumatol. 2011;25:241-7. https://doi.org/10.1016/j.berh.2011.01.016.

32. Mease PJ, Spaeth M, Clauw DJ, et al. Estimation of minimum clinically important difference for pain in fibromyalgia. Arthritis Care Res (Hoboken) 2011;63:821-6. https://doi.org/10.1002/acr.20449. 
33. Bennett RM, Friend $R$, Jones $K D$, et al. The revised fibromyalgia impact questionnaire (FIQR): validation and psychometric properties. Arthritis Res Ther. 2009;11:R120. https://doi.org/10.1186/ar2783.

34. Bennett RM, Bushmakin AG, Cappelleri JC, et al. Minimal clinically important difference in the fibromyalgia impact questionnaire. J Rheumatol. 2009;36: 1304-11. https://doi.org/10.3899/jrheum.081090.

35. Üçeyler N, Häuser W, Sommer C. Systematic review with meta-analysis: cytokines in fibromyalgia syndrome. BMC Musculoskelet Disord. 2011;12:245

36. Bidonde J, Busch AJ, Schachter CL, et al. Aerobic exercise training for adults with fibromyalgia. Cochrane Database Syst Rev. 2017. https://doi.org/10. 1002/14651858.CD012700

37. Palstam A, Mannerkorpi K. Work ability in fibromyalgia: an update in the 21st century. Curr Rheumatol Rev. 2017;13:180-7. https://doi.org/10.2174/ 1573397113666170502152955.

38. Staud R. Abnormal pain modulation in patients with spatially distributed chronic pain: fibromyalgia. Rheum Dis Clin North Am. 2009;35:263-74.

39. Gracely RH, Petzke F, Wolf JM, Clauw DJ. Functional magnetic resonance imaging evidence of augmented pain processing in fibromyalgia. Arthritis Rheum. 2002;46:1333-43. https://doi.org/10.1002/art.10225.

40. Desmeules JA, Cedraschi C, Rapiti E, et al. Neurophysiologic evidence for a central sensitization in patients with fibromyalgia. Arthritis Rheum. 2003;48: 1420-9. https://doi.org/10.1002/art.10893.

41. Malcangio M, Bowery NG, Flower RJ, Perretti M. Effect of interleukin-1 $\beta$ on the release of substance P from rat isolated spinal cord. Eur J Pharmacol. 1996;299:113-8. https://doi.org/10.1016/0014-2999(95)00845-4.

42. Janik JE, Miller $\mathrm{LL}$, Longo $\mathrm{DL}$, et al. Phase II trial of interleukin 1a and indomethacin in treatment of metastatic melanoma. J Natl Cancer Inst. 1996;88:44-9. https://doi.org/10.1093/jnci/88.1.44.

43. Wallace DJ, Linker-Israeli M, Hallegua D, et al. Cytokines play an aetiopathogenetic role in fibromyalgia: a hypothesis and pilot study. Rheumatology. 2001;40:743-9. https://doi.org/10.1093/rheumatology/40.7. 743.

44. Ernberg M, Christidis N, Ghafouri B, et al. Plasma cytokine levels in fibromyalgia and their response to 15 weeks of progressive resistance exercise or relaxation therapy. Mediators Inflamm. 2018;2018:3985154. https://doi.org/10.1155/2018/3985154.

45. Moltó A, Etcheto A, Gossec L, et al. Evaluation of the impact of concomitant fibromyalgia on TNF alpha blockers' effectiveness in axial spondyloarthritis: results of a prospective, multicentre study. Ann Rheum Dis. 2018:77:533-40. https://doi.org/10.1136/annrheumdis-2017-212378.

\section{Publisher's Note}

Springer Nature remains neutral with regard to jurisdictional claims in published maps and institutional affiliations.

Ready to submit your research? Choose BMC and benefit from:

- fast, convenient online submission

- thorough peer review by experienced researchers in your field

- rapid publication on acceptance

- support for research data, including large and complex data types

- gold Open Access which fosters wider collaboration and increased citations

- maximum visibility for your research: over $100 \mathrm{M}$ website views per year

At $\mathrm{BMC}$, research is always in progress.

Learn more biomedcentral.com/submissions 